\title{
AMIDO RESISTENTE: APLICAÇÕES E MÉTODOS DE PRODUÇÃO
}

LUÍS FERNANDO POLESI*

\begin{abstract}
A presente revisão de literatura teve por objetivo fornecer subsídios para o melhor entendimento do conceito de amido resistente (AR), responsável por elevar o teor de fibra dietética nos alimentos, com reduzida modificação sensorial. Foram abordados a composição do grânulo de amido, sua digestibilidade, os tipos de AR e como podem ser afetados pelo processamento, a aplicação de AR em alimentos e métodos para sua produção. Conclui-se que há a necessidade de mais pesquisas no que se refere à aplicação prática de AR em alimentos com o intuito de melhorá-los nutricionalmente, aumentando o consumo de fibra alimentar da população brasileira.
\end{abstract}

* Doutorando, Programa de Pós-graduação em Ciências, Centro de Energia Nuclear na Agricultura, Universidade de São Paulo, Piracicaba, SP (e-mail: Ifpolesi@usp.br). 


\section{INTRODUÇÃO}

O amido, maior fonte dietética de carboidratos, é o polissacarídeo de armazenamento mais abundante nas plantas, sendo sintetizado como grânulos nos cloroplastos de folhas verdes e amiloplastos de sementes, raízes e tubérculos. O reconhecimento da digestão e absorção incompleta do amido no intestino delgado, como fenômeno normal, tem criado interesse nas frações do amido não digeríveis. Essas frações são chamadas de amidos resistentes e estudos intensivos mostraram que apresentam funções fisiológicas similares àquelas das fibras dietéticas (EERLINGEN e DELCOUR 1995; ENGLYST, KINGMAN e CUMMINGS, 1992; SAJILATA, SINGHAL e KULKARNI, 2006).

A indústria de alimentos moderna, com a produção crescente de enorme variedade de produtos alimentícios, requer amidos que possam tolerar ampla gama de técnicas e condições de processamento. Tais demandas são satisfeitas pela modificação de amidos nativos com métodos químicos, físicos e enzimáticos, que podem levar a formação de resíduos indigeríveis. Por essa razão, os métodos outrora utilizados somente com o objetivo de modificação de amido passaram a ser empregados para potencializar a produção dessa fração indigerível devido a sua importância para a saúde (SAJILATA, SINGHAL e KULKARNI, 2006). Sendo assim, a presente revisão teve por objetivo fornecer subsídios para o melhor entendimento do conceito de amido resistente, suas aplicações, bem como os processos pelos quais pode ser obtido.

\section{AMIDO}

O amido, principal substância de reserva nas plantas superiores, é fonte primária de energia armazenada que fornece de 70 a $80 \%$ das calorias consumidas pelo homem no mundo. Define-se o amido como um polissacarídeo composto por unidades de glicose unidas por ligações glicosídicas $\alpha-1,4$ e $\alpha-1,6$. Apresenta-se na forma de grânulos de tamanhos e formatos variados, que são insolúveis em água fria (CEREDA et al., 2001; THOMAS e ATWELL, 1999).

Duas macromoléculas formam o grânulo de amido, ou seja, a amilose e a amilopectina. A amilose, macromolécula essencialmente linear, é formada por unidades de D-glicose ligadas em $\alpha-1,4$, com menos de $0,1 \%$ de ramificação (ligações $\alpha-1,6$ ). Apresenta grau de polimerização entre 500 e 2000 unidades de glicose e massa molecular média de $1,5 \times 10^{5}$ a $10^{6}$. A amilopectina, componente ramificado do amido, é formada por unidades de D-glicose unidas em $\alpha-1,4$ e $\alpha-1,6$, sendo essa última responsável pela ramificação da molécula. Apresenta grau de polimerização da ordem de $10^{4}$ a $10^{5}$, massa molecular média de $0,5 \times 10^{8}$ a $10^{9}$ e comprimento variável das ramificações, sendo comum a presença de 20 a 30 unidades de glicose (BELLO-PÉREZ, MONTEALVO e ACEVEDO, 2006; CEREDA et al., 2001).

Na planta, o amido é armazenado como corpos intracelulares parcialmente cristalinos (15 a 45\% de cristalinidade) denominados grânulos. Por meio de difração de raios $X$ podem-se distinguir três tipos de grânulos que, dependendo de sua forma e estrutura cristalina, denominamse A, B e C (CEREDA et al., 2001; ZOBEL, 1988). As cadeias externas relativamente curtas das moléculas de amilopectina (entre 23 e 29 unidades de glicose) favorecem a formação de polimorfos cristalinos tipo A, encontrados nos amidos de cereais. Já as cadeias externas maiores das moléculas de amilopectina de tubérculos (entre 30 e 44 unidades de glicose) favorecem a formação de polimorfos do tipo $B$, encontrados em amido de banana, amidos retrogradados e amidos ricos em amilose. O polimorfo tipo $C$, composto por moléculas de amilopectina de cadeias com 26 a 29 moléculas de glicose, é considerado intermediário entre os tipos A e B, sendo característico de amido de leguminosas e sementes (ELIASSON e GUDMUNDSSON, 2006; SAJILATA, SINGHAL e KULKARNI, 2006). 
O aquecimento do amido na presença de água em excesso promove expansão e solubilidade dos grânulos. Ao longo do tempo, o calor faz com que os grânulos continuem a se expandir e a amilose passa a ser lixiviada para a fase aquosa entre os grânulos, causando aumento crescente da viscosidade da amostra. A ruptura da estrutura granular, o inchamento, a hidratação e solubilização das moléculas de amido em conjunto definem o processo de gelatinização. Com o resfriamento da pasta de amido, após sua gelatinização, as cadeias do amido perdem energia e as pontes de hidrogênio tornam-se mais fortes, fazendo com que as moléculas de amilose apresentem tendência a se associar por pontes de hidrogênio com moléculas de amilose adjacentes, formando estrutura ordenada, cujo processo é conhecido como retrogradação (BELLO-PÉREZ, MONTEALVO e ACEVEDO, 2006; HOSENEY, 1994).

\section{DIGESTIBILIBADE DO AMIDO}

O amido é potencialmente digerível pelas enzimas amilolíticas secretadas no sistema digestivo humano, pois apresenta somente ligações a-glicosídicas (ENGLYST e HUDSON, 1996). No entanto, o amido apresenta digestibilidade variada e, até mesmo, pode não ser digerido pelo organismo. De acordo com Englyst, Kingman e Cummings (1992), o amido pode ser classificado dependendo da velocidade com a qual o alimento é digerido in vitro (incubação com amilase pancreática e amiloglucosidase a $37^{\circ} \mathrm{C}$ ) em:

- amido rapidamente digerível (ARD), quando digerido em 20 minutos;

- amido lentamente digerível (ALD), quando digerido entre 20 e 120 minutos; e

- amido resistente (AR), quando resiste à ação das enzimas digestivas após 120 minutos.

Define-se a soma do amido e dos produtos de sua degradação que não são absorvidos no intestino delgado de indivíduos saudáveis como AR (ENGLYST, KINGMAN e CUMMINGS, 1992). O AR, componente natural, pode ser encontrado em alimentos crus como batata, ervilha e grão-de-bico, que contêm AR em níveis de 4,4; 10,5 e 9,6\%, respectivamente (POMERANZ, 1992; USP, 2010), ou ainda em alimentos processados como pães, flocos de milho e feijão, que contêm AR em níveis de 1; 3 e 5\%, respectivamente (ENGLYST, KINGMAN e CUMMINGS, 1992).

O principal interesse em relação ao AR envolve seu papel fisiológico. Por não ser digerido no intestino delgado torna-se substrato para fermentação pelas bactérias anaeróbicas do cólon, razão pela qual o AR é considerado agente prebiótico. Assim, essa fração compartilha muitas das características e benefícios atribuídos à fibra alimentar no trato gastrintestinal (MUIR e O'DEA, 1992). Os produtos dessa fermentação são os ácidos graxos de cadeia curta, acético, propiônico e butírico, além de gases como hidrogênio, dióxido de carbono e metano (TOPPING e CLIFTON, 2001).

Estudos mostraram que a fermentação apresenta efeitos benéficos à saúde como o favorecimento da vasodilatação, aumento da absorção de água e sais, prevenção de colite ulcerativa, diminuição do risco de câncer de cólon, redução da constipação, inibição da síntese de colesterol, melhor controle do diabetes devido ao baixo índice glicêmico e reduções nos níveis de colesterol LDL (lipoproteína de baixa densidade) e de triglicerídeos na hiperlipidemia (FERREIRA, 2003; TOPPING e CLIFTON, 2001; YUE e WARING, 1998; JENKINS et al., 1998). O AR também é importante na dieta devido suas interações com outros componentes, incluindo não só os macronutrientes como lipídeos e proteínas, mas também micronutrientes como minerais (BROWN, 2004).

\subsection{TIPOS DE AMIDO RESISTENTE}

O amido se torna resistente à ação enzimática por diversos fatores, que caracterizam o AR 
em cinco tipos diferentes conforme fator específico de resistência.

A forma física do alimento pode impedir o acesso da amilase pancreática e diminuir a digestão do amido, fato que caracteriza o amido resistente tipo $1\left(\mathrm{AR}_{1}\right.$ - fisicamente inacessível), ou seja, torna-se resistente simplesmente porque as enzimas amilolíticas não têm acesso ao mesmo. Essa resistência do amido à digestão pode ocorrer se o amido estiver contido numa estrutura inteira ou parcialmente rompida da planta, como nos grãos, e se as paredes celulares rígidas inibirem o seu intumescimento, como nas leguminosas (NUGENT, 2005; WALTER, SILVA e EMANUELLI, 2005). O $\mathrm{AR}_{1}$ é altamente afetado pela mastigação e por etapas do processamento, como a moagem. Medese quimicamente $\circ \mathrm{AR}_{1}$ por meio da diferença entre a glicose liberada pela digestão enzimática de uma amostra homogeneizada e aquela liberada de amostra não homogeneizada (SAJILATA, SINGHAL e KULKARNI, 2006).

Em grânulos de amido nativo, o amido está firmemente acumulado num padrão radial e relativamente desidratado. Essa estrutura compacta limita a acessibilidade das enzimas digestivas e caracteriza o amido resistente tipo $2\left(\mathrm{AR}_{2}\right.$ - grânulos de amido resistente). Embora o grau de resistência dependa da fonte, geralmente grânulos com padrão de cristalinidade dos tipos $B$ e $C$ tendem a ser mais resistentes à digestão enzimática que os polimorfos do tipo $\mathrm{A}$. $\mathrm{OAR}$, pode ser encontrado em amido de milho e ervilha com altos teores de amilose, banana verde e batata. Além disso, sua resistência pode ser diminuída com o processamento e o cozimento dos alimentos. É quimicamente medido como a diferença entre a glicose liberada pela digestão enzimática de uma amostra homogeneizada e fervida e aquela de amostra não homogeneizada e não fervida (LOBO e SILVA, 2003; POLESI, SARMENTO e ANJOS, 2011; SAJILATA, SINGHAL e KULKARNI, 2006; THEMEIER et al., 2005; WALTER, SILVA e EMANUELLI, 2005).

$O$ processo de retrogradação caracteriza o amido resistente tipo $3\left(\mathrm{AR}_{3}\right.$ - amido retrogradado). A reestruturação proveniente do processo de retrogradação dificulta o acesso enzimático, prejudicando a digestibilidade do amido (LOBO e SILVA, 2003; SAJILATA, SINGHAL e KULKARNI, 2006). $O \mathrm{AR}_{3}$ é quimicamente medido como a fração que resiste a dispersão por fervura e digestão enzimática, sendo completamente resistente à digestão pela amilase pancreática (SAJILATA, SINGHAL e KULKARNI, 2006). Esse tipo de AR sofre influência das condições de processamento, teor de amilose e tempo/temperatura de armazenagem.

Com o objetivo de atender necessidades específicas da indústria de alimentos, produtos derivados do amido estão em constante desenvolvimento. Esses incluem os amidos substituídos quimicamente com grupamentos ésteres, fosfatos e éteres, bem como amidos com ligações cruzadas. Tais amidos modificados caracterizam o amido resistente tipo 4 ( $\mathrm{AR}_{4}$ - amido modificado). Modificações como conversão, substituição e ligações cruzadas podem dificultar a digestão por bloquear o acesso das enzimas e formar ligações atípicas (FUENTES-ZARAGOZA et al., 2011; LOBO e SILVA, 2003; NUGENT, 2005; SAJILATA, SINGHAL e KULKARNI, 2006).

A amilose pode se complexar com lipídeos, formando estrutura rígida, que restringe a expansão dos grânulos de amido durante o processo de cocção. O complexo amilose-lipídeo, resistente à hidrólise enzimática, caracteriza o amido resistente tipo $5\left(\mathrm{AR}_{5}-\right.$ complexo amiloselipídeo). No geral, a estrutura e a quantidade de complexo amido-lipídeo dependem da fonte botânica e ocorre mais comumente em amidos com alto teor de amilose, mais suscetíveis a retrogradação (FUENTES-ZARAGOZA et al., 2011; HASJIM et al., 2010).

A categorização do AR (tipos 1, 2, 3, 4 e 5) fornece a base conceitual para sua diferenciação. Entretanto, essas categorias podem limitar o entendimento do AR porque podem sugerir que há homogeneidade dentro de cada tipo, e que a diferenciação entre os tipos é simples, o que na realidade não ocorre (THOMPSON, 2000).

O processamento dos alimentos crus, na maioria dos casos, degrada o $A R_{1}$ e $\circ A R_{2}$, mas pode produzir $\mathrm{AR}_{3}$ devido à retrogradação da amilose (GONZÁLEZ-SOTO et al., 2006). O $\mathrm{AR}_{3}$ parece ser o tipo de maior interesse devido à sua estabilidade térmica, que permite que seja estável 
na maioria das operações de cozimento normais, ou seja, possibilita seu uso como ingrediente em ampla variedade de alimentos convencionais, mantendo sua resistência à digestão (FARAJ, VASANTHAN e HOOVER, 2004; PONGJANTA et al., 2009).

\section{APLICAÇÕES DO AMIDO RESISTENTE}

O amido resistente geralmente é encontrado como componente do alimento, formado durante seu processamento ou como ingrediente contendo AR. O objetivo de incluir ingrediente com alto teor de AR está relacionado com a funcionalidade física, estabilidade de processamento e funcionalidade nutricional. A funcionalidade física do ingrediente contendo AR envolve as características físicas apropriadas do alimento, tais como textura, capacidade de se ligar à água, etc. A estabilidade de processamento do AR torna-se importante para preservar a sua funcionalidade nutricional. A funcionalidade nutricional, por sua vez, pode envolver tanto a resistência à digestão no intestino delgado quanto à resistência à fermentação no cólon (THOMPSON, 2000).

Alguns processamentos de alimentos, como esterilização, forneamento e secagem em altas temperaturas, aumentam o nível de AR. Entretanto, em outros procedimentos, como cozimento, os amidos perdem sua resistência. O uso de AR comercial que pode resistir a certos processos permite que produtos sejam formulados com aumento no nível de fibra dietética total. Alguns amidos resistentes também têm características físicas únicas que se traduzem em propriedades funcionais que podem destacar o alimento. O AR pode ser utilizado isoladamente, como fonte de fibra, ou em combinação com fibras convencionais para se atingir níveis mais elevados (LUNARDINI, 2005; PEREIRA, 2007; YUE e WARING, 1998).

A National Starch, empresa multinacional produtora de amidos, desenvolveu diversos amidos resistentes, denominados NOVELOSE $®$, que apresentam baixa capacidade de retenção de água, pequeno tamanho de partículas e sabor neutro (ZELAYA, 2000). O NOVELOSE 260 apresenta vantagens quando comparado com as fibras convencionais por ser branco, ter sabor neutro e tamanho de partícula entre 10-15 $\mu \mathrm{m}$. Também apresenta teor calórico reduzido $\left(1,6 \mathrm{kcal}^{-\mathrm{g}^{-1}}\right) \mathrm{e}$ pode ser utilizado como agente de corpo complementar em formulações com menor valor calórico ou sem gordura. Com o teor de fibra dietética total de aproximadamente $60 \%$, esse AR pode ser empregado sozinho ou como complemento funcional de outras fontes de fibras, com a vantagem de poder ser rotulado simplesmente como "amido de milho". Outro aspecto importante do NOVELOSE 260 envolve a capacidade de retenção de água menor do que outras fontes de fibras convencionais. Por absorver menos água, os ajustes na formulação e no processamento são substancialmente minimizados (PEREIRA, 2007).

Pães produzidos com fibras convencionais, por exemplo, têm alta capacidade de absorção de água, alterando a reologia da massa. Isso, por sua vez, pode resultar em dificuldade na moldagem e fatiabilidade, bem como no possível aumento no tempo de forneamento. Além disso, pães com alto teor de fibras, geralmente apresentam cor escura, textura arenosa, sabor característico e reduzido volume de expansão, características não apreciadas pelo consumidor (PEREIRA, 2007). Em contrapartida, pães produzidos com AR apresentam massas mais facilmente manuseáveis, sabor neutro, sensação na boca e textura mais suaves e lisas e exigem menos ajustes na formulação. Dessa forma, o pão branco com AR tem melhor volume, miolo mais uniforme e estrutura celular mais fina do que o pão com fibras convencionais (LUNARDINI, 2005).

Aplicações de amidos resistentes são apropriadas para a maioria dos produtos com baixa umidade. Muitos produtos de panificação e cereais são conhecidos como fonte de fibras e outros, como muffins e brownies, não são considerados normalmente como alimentação saudável. Entretanto, esses produtos podem ser preparados com AR como fonte de fibras, aumentando seu valor nutricional. Estudos têm mostrado que a utilização de AR mantém os produtos com 
características organoléticas melhores do que fontes de fibras convencionais. Em brownies, bolos e cookies, os amidos resistentes proporcionam textura suave, mantida durante a vida útil do produto (LUNARDINI, 2005; YUE e WARING, 1998).

Como ingrediente, o AR promove crocância para biscoitos e sua habilidade de expansão pode propiciar melhores texturas em cereais matinais, por exemplo. Também em cereais matinais, 0 ingrediente AR provê aumento do tempo de permanência da crocância em meio líquido. Devido ao baixo teor calórico, o AR pode ser usado em produtos com apelos diet e light. Como fibra funcional, o AR possibilita formular produtos com maior apelo e maior palatabilidade quando comparado com os produtos formulados com as fibras convencionais (BROWN, 2004; PEREIRA, 2007; ZELAYA, 2000).

\section{MÉTODOS PARA PRODUÇÃO DE AMIDO RESISTENTE}

Existem muitos estudos sobre o desenvolvimento de produtos com maiores teores de amido resistente, bem como ingredientes ricos em amido resistente para serem adicionados aos alimentos elevando seu teor de fibras.

\subsection{AMIDO RESISTENTE DO TIPO 1}

A literatura descreve tratamentos de redução de tamanho para diminuir $A R_{1}$, mas há pouca informação sobre como aumentar $A R_{1}$ pelo processamento. $A$ resistência enzimática do $A R_{1}$ baseia-se na inacessibilidade da enzima ao amido, mediante barreira física, portanto qualquer fonte amilácea poderia ficar presa no alimento de modo a se tornar inacessível às enzimas. Se esse tipo de AR fizer parte de ingrediente a ser utilizado na produção de determinado alimento, seu teor de AR final vai depender da manutenção do material inacessível nas condições do processamento (THOMPSON, 2000).

\subsection{AMIDO RESISTENTE DO TIPO 2}

Os amidos de batata e banana verde apresentam quantidades consideráveis de $A R_{2}$, mas perdido facilmente com o processamento térmico (temperaturas elevadas), o que faz com que seu uso seja limitado. Amidos com alto teor de amilose (maior que 50\%), normalmente apresentam teores elevados de $\mathrm{AR}_{2}$, com maior estabilidade térmica. Como exemplo tem-se o amido de ervilha rugosa, que contém $61 \%$ de amilose e perde $60 \%$ de AR com o processamento. Já o amido de grãode-bico com $29 \%$ de amilose perde $92 \%$ de AR com o mesmo processamento. Portanto, alto teor de amilose favorece a manutenção do AR mesmo com o processamento (POLESI, SARMENTO e ANJOS, 2011).

Existem diversos genótipos de milho com alto teor de amilose e teores elevados de $\mathrm{AR}_{2}$. Milhos com teores de amilose que variam de 60 a $85 \%$ apresentam teor de AR de 20 a 35\%, que após processamento térmico ficam entre 11 e $42 \%$. Assim, para os milhos com mais de $80 \%$ de amilose, o teor de AR além de não ser perdido com temperaturas elevadas, ainda é aumentado (LI et al., 2008).

Diferentemente da batata ou da banana verde, grande parte do AR de amidos com alto teor de amilose se mantém após a fervura em excesso de água, sendo estável nas condições de processamento mais comuns. Assim, esses amidos são de interesse prático como fonte de $\mathrm{AR}_{2}$. Esse comportamento físico sugere que a natureza do $\mathrm{AR}_{2}$ dos amidos com teor de amilose elevado difere da natureza do $\mathrm{AR}_{2}$ de amidos com teor de amilose reduzido, caso da batata ou da banana. Isso ocorre porque os amidos com mais amilose apresentam estrutura granular diferenciada, com expansão reduzida quando em solução aquosa e temperaturas elevadas, portanto o processo de gelatinização desses amidos também difere. A perda da estrutura granular ocorre lentamente em 
ampla faixa de temperatura o que, provavelmente, faz com que eles mantenham a resistência às enzimas, mesmo depois de passarem por processo de fervura (BOLTZ e THOMPSON, 1999; THOMPSON, 2000).

Existem formas de se elevar o teor de $\mathrm{AR}_{2}$ dos amidos por combinações de temperatura, umidade e tempo de modo a manter sua estrutura granular (THOMPSON, 2000). O tratamento físico do amido granular para modificar sua estrutura sem a gelatinização ou fusão dos grânulos recebe a denominação de tratamento hidrotérmico (JACOBS e DELCOUR, 1998). Devido à estrutura semicristalina do grânulo nativo, o tratamento hidrotérmico pode ser utilizado para melhorar a ordem da fração cristalina ou aumentar a proporção dessa fração (THOMPSON, 2000).

Shi e Trzasko (1997) descreveram o tratamento de milho com alto teor de amilose em temperaturas de 60 a $160^{\circ} \mathrm{C}$, cuja temperatura variou conforme o teor de umidade. As combinações de temperatura/umidade foram escolhidas para assegurar que a estrutura granular não fosse perdida. $\mathrm{O}$ aquecimento do amido a $100^{\circ} \mathrm{C}$ com $37 \%$ de água por $1-4$ horas aumentou para $40 \%$ o teor de AR, que era de apenas $12 \%$ no amido inicial. Sais inorgânicos podem ser adicionados nesse sistema para inibir a expansão dos grânulos e, assim, ajudar a reter a estrutura granular em altas temperaturas para teor específico de umidade (THOMPSON, 2000).

\subsection{AMIDO RESISTENTE DO TIPO 3}

O processo e os conhecimentos sobre gelatinização de amido não são novos, no entanto outros enfoques têm demonstrado que a retrogradação do amido gelatinizado induz a formação de $A R$, sendo esse processo essencial para o desenvolvimento de $A R_{3}$. Assim, o processamento dos alimentos amiláceos tem repercussões importantes no conteúdo de AR dos produtos finais, pois podem afetar a gelatinização e a retrogradação do amido (ESCARPA e GONZÁLEZ, 1997; WANG, JIN e YUAN, 2007).

Os métodos para produção de $\mathrm{AR}_{3}$ baseiam-se na gelatinização do amido com posterior retrogradação, sendo mais empregados os de autoclavagem, cocção, extrusão e irradiação por micro-ondas. Após tais processos, são utilizadas técnicas que potencializam a retrogradação do amido como o resfriamento, ou o uso de diversos ciclos de cocção e resfriamento, visando a obtenção de maior teor de $\mathrm{AR}_{3}$ (SAJILATA, SINGHAL e KULKARNI, 2006).

Rosin, Lajolo e Menezes (2002), trabalhando com alimentos cozidos e armazenados sob baixa temperatura $\left(-20^{\circ} \mathrm{C}\right)$ por 7 e 30 dias, observaram indução da formação de AR. $\mathrm{O}$ aumento do teor de AR foi significativo para 30 dias de armazenamento em todos os alimentos estudados (arroz, batata, ervilha, lentilha, macarrão, grão-de-bico, milho, polenta, feijão e pão francês).

Técnicas de redução da massa molecular do amido por meio de ácido ou desramificação da amilopectina por ação de enzima podem ser utilizados adicionalmente ao processo de obtenção de $\mathrm{AR}_{3}$ (GONZALEZ-SOTO et al., 2004; LEONG, KARIM e NORZIAH, 2007; POLESI e SARMENTO, 2011; POLESI, SARMENTO e FRANCO, 2011; VASANTHAN e BATTHY, 1998). O uso dessas técnicas visa à obtenção de maior número de cadeias lineares para facilitar o pareamento, que por consequência aumentam o teor de amido retrogradado após a gelatinização e o resfriamento.

\subsubsection{Autoclavagem}

Dentre os tratamentos térmicos, a autoclavagem consiste no método mais utilizado para produção de $\mathrm{AR}_{3}$ em altas temperaturas por longo tempo variando-se o tempo de resfriamento e os ciclos de autoclavagem e resfriamento (Teixeira et al., 1998). Vários estudos demonstraram que a autoclavagem aumenta o teor de AR de diferentes fontes botânicas (GONZÁLEZ-SOTO et al., 2006, GONZÁLEZ-SOTO et al., 2004; LEONG, KARIM e NORZIAH, 2007).

$\mathrm{O}$ amido, em diferentes teores de umidade, que passa por tratamento de autoclavagem em várias temperaturas e tempos de processamento, apresenta aumento considerável no teor de AR. O amido de trigo autoclavado tem $9 \%$ de AR comparado com menos de $1 \%$ do amido de trigo 
nativo (SILJESTROM e ASP, 1985). O amido de trigo autoclavado contendo $6,2 \%$ de AR aumentou para $7,8 \%$ após 3 ciclos adicionais de cozimento e resfriamento (BJORCK et al., 1987). A farinha de ervilha passou de 5,6 para 9,4\% de AR e a farinha de grão-de-bico de 2,6 para 7,1\% apenas com o processo de autoclavagem/resfriamento (DEL BEM et al., 2011).

O teor de AR do amido de milho com alto teor de amilose (70\%) pode ser elevado para $40 \%$ quando submetido a 20 ciclos de autoclavagem e resfriamento (EERLINGEN e DELCOUR, 1995). Teixeira et al. (1998) triplicaram o teor de AR no amido normal de milho, após tratamento térmico com autoclavagem a $121^{\circ} \mathrm{C}$ por uma hora e o amido a $70 \%$ de umidade.

\subsubsection{Hidrólise do amido}

A hidrólise envolve principalmente a quebra das moléculas do amido em fragmentos de massa molecular menor, aumentando o número de moléculas lineares menores que as de amilose do amido nativo, o que resulta na elevação da tendência de retrogradação sob resfriamento e repouso do amido gelatinizado. Portanto, a hidrólise consiste em pré-tratamento que visa aumentar as possibilidades de se obter $\mathrm{AR}_{3}$ com a autoclavagem e retrogradação do amido (GONZÁLEZSOTO et al., 2004; LEONG, KARIM e NORZIAH, 2007; POLESI e SARMENTO, 2011; POLESI, SARMENTO e FRANCO, 2011; VASANTHAN e BHATTY, 1998).

O processo de hidrólise pode ocorrer por duas vias: a química (ácidos, calor e pressão) ou a enzimática (uso de enzimas). A hidrólise enzimática apresenta a vantagem da especificidade de quebra, permitindo maior controle sobre os produtos obtidos, porém apresenta custo elevado. A hidrólise ácida envolve menor custo, mas em contrapartida não se tem muito controle sobre a quebra que o ácido realiza na molécula de amido (SUMERLY et al., 2003).

O processo de desramificação do amido tem sido proposto como método auxiliar, antes da autoclavagem, com o objetivo de tornar cadeias de amilopectina lineares e, portanto, mais facilmente retrogradáveis (LEONG, KARIM e NORZIAH, 2007). Alguns amidos de fontes botânicas, como a banana e o grão-de-bico, mostraram aumento de até $100 \%$ no teor de AR com o uso da enzima pululanase para desramificar o amido antes do processo de autoclavagem/resfriamento (GONZÁLEZ-SOTO et al. 2004; POLESI e SARMENTO, 2011).

Durante as fases iniciais do tratamento ácido ocorre a hidrólise da amilopectina nos pontos de ramificação ou próximo a eles, o que gera hidrolisado contendo fragmentos de amido (cadeias lineares, duplas hélices, porções cristalinas, etc.) semelhante ao resultado obtido com a hidrólise de pululanase. Esses fragmentos de amido participam, então, da formação de $\mathrm{AR}_{3}$ (VASANTHAN e BHATTY, 1998). Polesi, Sarmento e Franco (2011) obtiveram aumento de $45 \%$ no teor de AR em amido de ervilha rugosa tratado com ácido previamente ao processo de autoclavagem e resfriamento.

\subsection{AMIDO RESISTENTE DO TIPO 4}

A digestibilidade dos amidos modificados era estudada apenas sob a perspectiva de disponibilidade calórica e de segurança, mas não para produção de AR (THOMPSON, 2000). O uso das técnicas de oxidação, acetilação, hidroxipropilação e ligações cruzadas em amido de milho mostrou que a substituição (acetilação, hidroxipropilação) e a oxidação contribuíram para elevar a quantidade de AR no amido nativo, com aumento de até 200\% (CHUNG, SHIN e LIM, 2008). Em outro estudo com amido de milho para obtenção de AR por métodos de autoclavagem/resfriamento somado à modificação química de ligações cruzadas, o teor de AR passou de $0,3 \%$ no amido nativo para $43,4 \%$ no amido autoclavado/resfriado, tratado com trimetafosfato de sódio/tripolifosfato de sódio e ácido adípico (KIM et al., 2010). Dessa forma, a produção de $\mathrm{AR}_{4}$ é um campo mais novo que está sendo explorado com mais intensidade. 


\section{CONCLUSÃO}

O AR pode ser utilizado em diversos produtos alimentícios com o intuito de elevar seu teor de fibra dietética, com a vantagem de influenciar de forma reduzida as características organoléticas dos alimentos, quando comparado às fibras convencionais. A adição de AR nos alimentos para enriquecê-los nutricionalmente pode ser realizada de forma isolada ou em associação com fibras convencionais. Diversas técnicas de produção de AR tem sido desenvolvidas, com enfoque mais recente para o $A R_{4}$ e $A R_{5}$. Dessa forma, a escolha do ingrediente com alto teor de $A R$ vai depender da fonte botânica e do processo de obtenção, baseada nas características físico-químicas particulares que cada produto apresenta e nos atributos que se deseja adicionar a cada alimento.

\section{ABSTRACT}

\section{RESISTANT STARCH: APPLICATIONS AND METHODS OF PRODUCTION}

This review aimed to provide a basis for better comprehension of the resistant starch (RS) concept, responsible for raising the dietary fiber level in foods with reduced sensory changes. The main topics approached in this review were: starch granule composition, digestibility, RS types, how RS can be affected by processing, RS application in foods, and methods for RS production. It was concluded that are still required further researches regarding the RS practical application in food in order to improve them nutritionally, increasing dietary fiber intake of the Brazilian population.

KEY-WORDS: STARCH; DIGESTIBILITY; RESISTANT STARCH; FUNTIONAL PROPERTIES.

\section{REFERÊNCIAS}

1 BELLO-PÉREZ, L.A.; MONTEALVO, M.G.M.;ACEVEDO, E.A. Almidón: definición, estructura y propriedades. In: LAJOLO, F.M.; MENEZES, E.W. Carbohidratos em alimentos regionales iberoamericano. São Paulo: Edusp, 2006. cap. 1, p. 17-46.

2 BJORCK, I.; NYMAN, M.; PEDERSEN, P.; SILJESTROM, M.; ASP, N.G.; EGGUM, B.O. Formation of enzyme resistant starch during autoclaving of wheat starch: studies in vitro and in vivo. Journal of Cereal Science, v. 6, p. 159-72, 1987.

3 BOLTZ, K.W.; THOMPSON, D.B. Initial heating temperature and native lipids affects ordering of amylose during cooling of high-amylose starches. Cereal Chemistry, v.76, p. 204-212, 1999.

4 BROWN, I.L. Applications and uses of resistant starch. Journal of AOAC International, v. 87, n. 3, p. 727 732, 2004.

5 CEREDA, M.P; FRANCO, C.M.L.; DAIUTO, E.R.; DEMIATE, I.M.; CARVALHO L.J.C.B.; LEONEL, M.; VILPOUX, O.F.; SARMENTO, S.B.S. Propriedades gerais do amido. Campinas: Fundação Cargill, 2001. v. 1, 224 p. (Série Culturas de Tuberosas Amiláceas Latino Americanas).

6 CHUNG, H.J.; SHIN, D.H.; LIM, S.T. In vitro starch digestibility and estimated glycemic index of chemically modified corn starches. Food Research International, v. 41, p. 579-585, 2008.

7 DEL BEM, M.S.; POLESI, L.F.; SARMENTO, S.B.S.; ANJOS, C.B.P. Propriedades físico-químicas e sensoriais de massas alimentícias elaboradas com farinhas de leguminosas tratadas hidrotermicamente. Alimentos $\mathbf{e}$ Nutrição, 2011 (no prelo).

8 EERLINGEN, R.C.; DELCOUR, J.A. Formation, analysis, structure and properties of type III enzyme resistant starch. Journal of Cereal Science, v. 22, p. 129-38, 1995.

9 ELIASSON, A.N.; GUDMUNDSSON, M. Starch: physicochemical and functional aspects. In: ELIASSON, A.N. (Ed.) Carbohydrates in food. $2^{\text {nd }}$ ed. Boca Raton: CRC Press, 2006. chap. 9, p. 391-469.

10 ENGLYST, H.N.; HUDSON, G.J. The classification and measurement of dietary carbohydrates. Food Chemistry, v. 57, n. 1, p. 15-21, 1996. 
11 ENGLYST, H.N.; KINGMAN, S.M.; CUMMINGS, J.H. Classification and measurement of nutritionally important starch fractions. European Journal of Clinical Nutrition, v. 46, (Suppl 2), p. S33-S50, 1992.

12 ESCARPA, A.; GONZÁLEZ, M.C. Tecnología del almidón resistente. Food Science and Technology International, v. 3, p. 149-161, 1997.

13 FARAJ, A.; VASANTHAN, T.; HOOVER, R. The effect of extrusion cooking on resistant starch formation in waxy and regular barley flours. Food Research International, v. 37, p. 517-525, 2004.

14 FERREIRA, C.L.L.F. Prebióticos e probióticos: atualização e prospecção. Viçosa: Suprema Gráfica e Editora, 2003.

15 FUENTES-ZARAGOZA, E.; SÁNCHEZ-ZAPATA, E.; SENDRA, E.; SAYAS, E.; NAVARRO, C.; FERNÁNDEZLÓPEZ, J.; PÉREZ-ALVAREZ, J.A. Resistant starch as prebiotic: a review. Starch/Stärke, v. 63, p. 406-415, 2011.

16 GONZÁLEZ-SOTO, R.A.; AGAMA-ACEVEDO, E.; SOLORZA-FERIA, J.; RENDÓNVILLALOBOS, R.; BELLO-PÉREZ, L.A. Resistant starch made from banana starch by autoclaving and debranching. Starch/ Stärke, v. 56, p. 495-499, 2004.

17 GONZÁLEZ-SOTO, R.A.; SÁNCHEZ-HERNÁNDEZ, L.; SOLORZA-FERIA, J.; NÚÑEZSANTIAGO, C.; FLORES-HUICOCHEA, E.; BELLO-PÉREZ, L.A. Resistant starch production from non-conventional starch sources by extrusion. Food Science and Technology International, v. 12, n.1, p. 5-11, 2006.

18 HASJIM, J.; LEE, S.O.; HENDRICH, S.; SETIAWAN, S.; AI, Y.; JANE, J.L. Characterization of a novel resistant-starch and its effects on postprandial plasma-glucose and insulin responses. Cereal Chemistry, v. 87 , p. 257-262, 2010.

19 HOSENEY, R.C. Starch. In: HOSENEY, R.C. Principles of cereal: science and technology. $2^{\text {nd }}$ ed. St. Paul: American Association of Cereal Chemists, 1994. chap. 2, p. 29-64.

20 JACOBS, H.; DELCOUR, J. Hydrothermal modifications of granular starch, with retention of granular structure: a review. Journal of Agricultural and Food Chemistry, v. 46, p. 2895-2905, 1998.

21 JENKINS, D.J.A.; VUKSAN, V.; KENDALL, C.W.C.; WÜRSCH, P.; JEFFCOAT, R.; WARING, S.; MEHLING, C.C.; VIDGEN, E., AUGUSTIN, L.S.A.; WONG, E. Physiological effects of resistant starches on fecal bulk, short chain fatty acids, blood lipids and glycemic index. Journal of the American College of Nutrition, v. 17, n. 6, p. 609-616, 1998.

22 KIM, N.H.; KIM, J.H.; LEE, S.; LEE, H.; YOON, J.W.; WANG, R.; YOO, S.H. Combined effect of autoclavingcooling and cross-linking treatments of normal corn starch on the resistant starch formation and physicochemical properties. Starch/Stärk, v. 62, p. 358-363, 2010.

23 LEONG, Y.H.; KARIM, A.A.; NORZIAH, M.H. Effect of pullulanase debranching of sago (Metroxylon sagu) starch at subgelatinization temperature on the yield of resistant starch. Starch/Stärke, v. 59, p. 21-32, 2007.

24 LI, L.; JIANG, H.; CAMPBELL, M.; BLANCO, M.; JANE, J. Characterization of maize amylose-extender (ae) mutant starches. Part I: relationship between resistant starch contents and molecular structures. Carbohydrate Polymers, v. 74, p. 396-404, 2008.

25 LOBO, A.R.; SILVA, G.M. de L. Amido resistente e suas propriedades físico-químicas. Revista de Nutrição, v. 16, n. 2, p.219-226, 2003.

26 LUNARDINI, A.C. Como melhorar a textura, sabor e performance de produtos em panificação. Revista da ABAM, Paranavaí, v. 3, n. 11, 2005. Disponível em: <http://www.abam.com.br/revista/revista11/textura. php>. Acesso em: 10 dez. 2010.

27 MUIR, J.G.; O'DEA, K. Measurement of resistant starch: factors affecting the amount of starch escaping digestion in vitro. American Journal of Clinical Nutrition, v. 56, p. 123-127, 1992.

28 NUGENT, A.P. Health properties of resistant starch. Nutrition Bulletin, v. 30, p. 27-54, 2005.

29 PEREIRA, K.D. Amido resistente, a última geração no controle de energia e digestão saudável. Ciência e Tecnologia de Alimentos, v. 27(supl.), p. 88-92, 2007. 
30 POLESI, L.F.; SARMENTO, S.B.S.; FRANCO, C.M.L. Production and physicochemical properties of resistant starch from hydrolysed wrinkled pea starch. International Journal of Food Science and Technology, v. 46, p. 2257-2264, 2011.

31 POLESI, L.F.; SARMENTO, S.B.S. Structural and physicochemical characterization of resistant starch prepared using hydrolysis and heat treatments of chickpea starch. Starch/Stärke, v. 63, p. 226-235, 2011.

32 POLESI, L.F.; SARMENTO, S.B.S.; ANJOS, C.B.P. Composition and characterization of pea and chickpea starches. Brazilian Journal of Food Technology, v. 14, p. 74-81, 2011.

33 POMERANZ, Y. Research and development regarding enzyme-resistant starch (RS) in the USA: a review. European Journal of Clinical Nutrition, v. 46, (Suppl 2), p. 63S-68S, 1992.

34 PONGJANTA, J.; UTAIPATTANACEEP, A.; NAIVIKUL, O.; PIYACHOMKWAN, K. Effects of preheated treatments on physicochemical properties of resistant starch type III from pullulanase hydrolysis of high amylose rice starch. American Journal of Food Technology, v. 4, p. 79-89, 2009.

35 ROSIN, P.M.; LAJOLO, F.M.; MENEZES, E.W. Measurement and characterization of dietary starches. Journal of Food Composition and Analysis, v. 15, p. 367-377, 2002.

36 SAJILATA, M.G.; SINGHAL, R.S.; KULKARNI, P.R. Resistant starch - a review. Comprehensive Reviews in Food Science and Food Safety, v. 5, n. 1, p. 1-17, 2006.

37 SHI, Y.C.; TRZASKO, P.T. Process for producing amylase resistant granular starch, US Patent \# 5,593,503. Jun. $7^{\text {th }} 1995$, Jan. $14^{\text {th }}$ 1997. United States National Starch and Chemical Investment Holding Corporation, Wilmington. (http://www.freepatentsonline.com/5593503.html)

38 SILJESTROM, M.; ASP, N.G. Resistant starch formation during baking. Effect of baking time and temperature and variation in the recipe. Zeitschrift für Lebensmitteluntersuchung und - Forschung, v. 4, p. 1-18, 1985.

39 SURMELY, R.; ALVAREZ, H.; CEREDA, M. P.; VILPOUX, O. F. Hidrólise do amido. In: CEREDA, M. P.; VILPOUX, O. F. Culturas de tuberosas amiláceas latino americanas. São Paulo: Fundação Cargill, 2003. v. 3, p. 378-449.

40 TEIXEIRA, M.A.V.; CIACCO, C.F.; TAVARES, D.Q.; BONEZZI, A.N. Ocorrência e caracterização do amido resistente em amidos de milho e de banana. Ciência e Tecnologia de Alimentos, v. 18, p. 246-253, 1998.

41 THEMEIER, H.; HOLLMANN, J.; NEESE, U.; LINDHAUER, M.G. Structural and morphological factors influencing the quantification of resistant starch II in starches of different botanical origin. Carbohydrate Polymers, v. 61, p. 72-79, 2005.

42 THOMAS, D.J.; ATWELL, W. Practical for guides the food industry: starch. Saint Paul: Eagan Press, 1999. $94 \mathrm{p}$

43 THOMPSON, D.B. Strategies for the manufacture of resistant starch. Trends in Food Science \& Technology, v. 11, p. $245-253,2000$.

44 TOPPING, D.L.; CLIFTON, P.M. Short-chain fatty acids and human colonic function: roles of resistant starch and nonstarch polysaccharides. Physiological Reviews, v. 81, n. 3, p. 1031-1064, 2001.

45 UNIVERSIDADE DE SÃO PAULO (USP). Tabela brasileira de composição de alimentos (TBCA-USP 4.1). Disponível em: <http://www.fcf.usp.br/tabela/resultado.asp?IDLetter=T\&IDNumber=13>. Acesso em: 22 nov. 2010.

46 VASATHAN, T.; BATTHY, S. Enhancement of resistant starch (RS3) in amylomaize, barley, field pea and lentil starches. Starch/Stärke, v. 50, p. 286-291, 1998.

47 WALTER, M.; SILVA, L.P. da; EMANUELLI, T. Amido resistente: características físico-químicas, propriedades fisiológicas e metodologias de quantificação. Ciência Rural, v. 35, n. 4, p. 974-980, 2005.

48 WANG, J.; JIN, Z.; YUAN, X. Preparation of resistant starch from starch-guar gum extrudates and their properties. Food Chemistry, v. 101, p. 20-25, 2007. 
49 YUE, P.; WARING, S. Resistant starch in food applications. Cereal Foods World, v. 43, n. 9, p. 690-695, 1998.

50 ZELAYA, M.P. O papel da adesão e de amidos resistentes em snacks e cereais. Food Ingredients, v. 11, n. 9, p. 18-19, 2000.

51 ZOBEL, H.F. Starch crystal transformations and their industrial importance. Starch/Stärke, v. 40, p. 1-7, 1988. 